\title{
Transplantation of Autologous Sympathetic Ganglion into the Brain with Parkinson's Disease - Clinical Trial
}

\author{
Toru Itakura, Mitsukazu Nakai, Yoshitsugu Ooiwa and Norihiko Komai \\ Department of Neurological Surgery, Wakayama Medical College, \\ 27, 7 bancho, Wakayama 640, Japan
}

We have demonstrated that transplantation of the autologous cervical sympathetic ganglion into the brain ameliorated MPTP-induced parkinsonism in the monkey. According to the encouraging data from this animal model, we have applied this transplantation method to parkinsonian patients. Eight patients (45 - 59 years, 5 male and 3 female) underwent stereotactic transplantation of the autologous stellate ganglion into the unilateral caudate nucleus and putamen. Under local anesthesia a stereotactic frame was fixed to the patient's head, and the frame and patient's brain were simultaneously imaged to obtain the coordinates of the target points. Then the stellate ganglion was removed and cut into 100 pieces in a tissue culture solution. The small blocks of the ganglion were stereotaxically transplanted into the head of the caudate nucleus and anterior putamen. One week before transplantation, administration of L-dopa was stopped in all 8 patients. Pre- and postoperative states of the patients were carefully observed by a neurologist and were scored using the unified parkinsonism rating scale (UPRS), Hoehn \& Yahr's stage and four timed tests. Postoperative courses of the patients were encouraging. Seven out of 8 patients showed amelioration of parkinsonism, but one patient did not. Most patients showed amelioration of gait disturbance and bradykinesia. In contrast, tremor of the 7 patients seemed to be slightly aggravated 2 - 4 weeks after transplantation. No L-dopa administration was needed in these patients. During follow-up periods from 2 months to 1 year, the seven patients showed gradual and continuous improvement of parkinsonian symptoms, especially gait disturbance and bradykinesia. Unilateral transplantation resulted

\section{Results of Stellate Ganglion Transplant}

\begin{tabular}{|c|c|c|c|c|c|c|c|c|c|c|}
\hline \multirow{2}{*}{ case } & \multicolumn{5}{|c|}{ Response } & \multirow{2}{*}{ sex } & \multirow{2}{*}{ age } & \multirow{2}{*}{$\begin{array}{l}\text { Yahr } \\
\text { stage }\end{array}$} & \multirow{2}{*}{$\begin{array}{l}\text { Ganglion } \\
\mathrm{CA} \text { index }\end{array}$} & \multirow{2}{*}{$\begin{array}{l}\text { postop } \\
\text { bleeding }\end{array}$} \\
\hline & $1 \mathrm{~m}$ & $2 \mathrm{~m}$ & $3 \mathrm{~m}$ & $6 \mathrm{~m}$ & $1 y$ & & & & & \\
\hline 1 & ++ & ++ & ++ & ++ & ++ & $F$ & 45 & III & 0.18 & - \\
\hline 2 & - & - & - & - & & F & 52 & $I V \sim V$ & 0.03 & + \\
\hline 3 & + & + & + & + & & $F$ & 59 & IV & 0.09 & - \\
\hline 4 & ++ & ++ & ++ & & & $\mathbf{M}$ & 52 & III & 0.14 & - \\
\hline 5 & ++ & + & & & & $\mathbf{M}$ & 47 & 11 & 0.19 & - \\
\hline 6 & + & + & & & & $\mathbf{M}$ & 55 & III & 0.22 & - \\
\hline 7 & + & + & & & & $\mathbf{M}$ & 57 & III & 0.14 & - \\
\hline 8 & ++ & & & & & $\mathbf{M}$ & 52 & III & 0.05 & - \\
\hline
\end{tabular}


in bilateral improvement of bradykinesia as judged from the results of four timed tests. One patient showed no improvement of the symptoms and needed L-dopa treatment even after the operation. In this case, the preoperative patient's state was severe (4 - 5 in Yahr's stage), and catecholamine cells in the stellate ganglion observed under histofluorescence were severely damaged. Also a small hemorrhage was observed in the transplanted site under postoperative CT scan. As complications of this surgery, all patients revealed Horner's syndrome such as ptosis and miosis of the eye on the stellate ganglion operation side.

These clinical data suggest that the autologous cervical sympathetic ganglion can be a donor tissue for neural transplantation in Parkinson's disease.

\section{REFERENCE}

1. Itakura $\mathrm{T}$ et al. Autotransplantation of the superior cervical ganglion into the brain. J Neurosurg 1988; 68: $555-560$. 

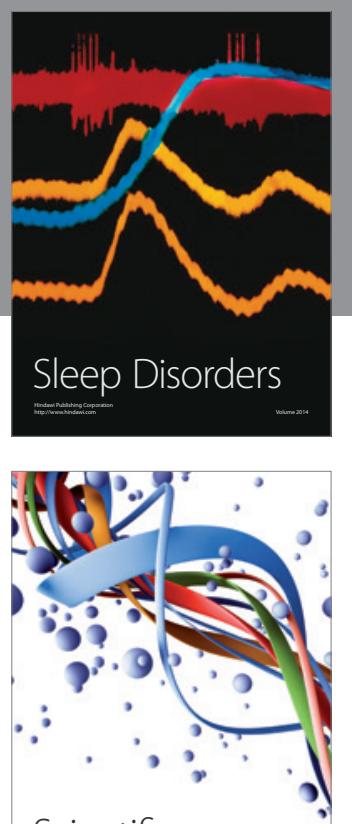

Scientifica
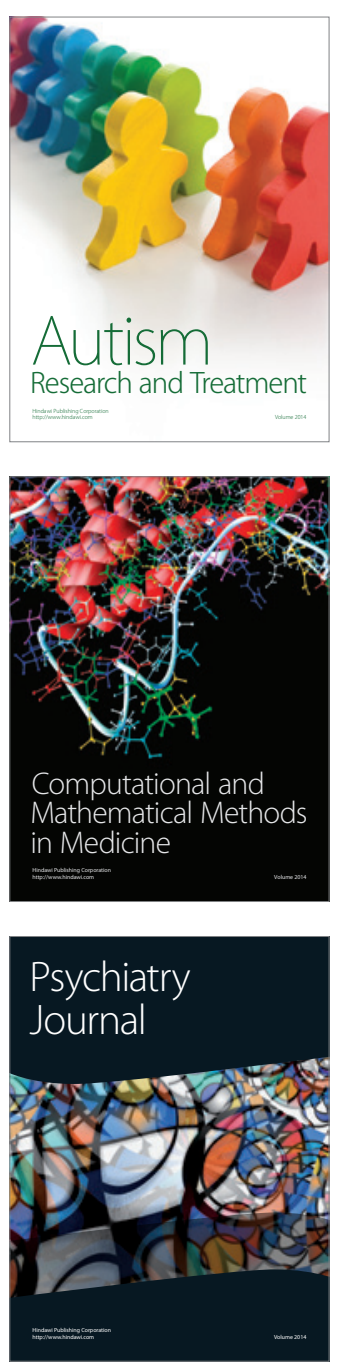
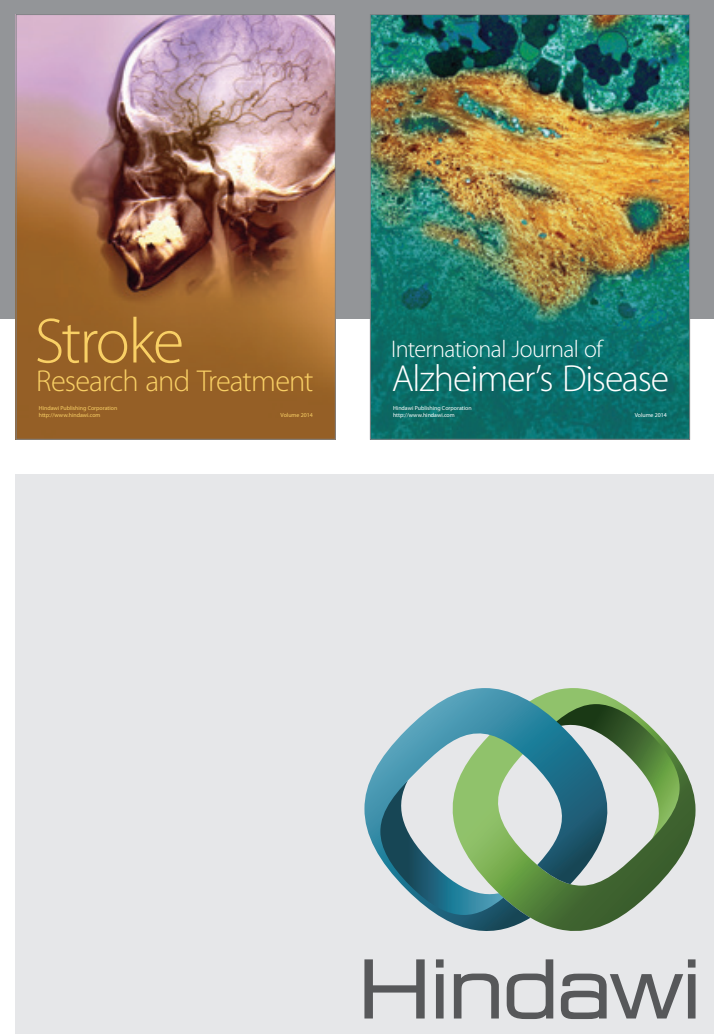

Submit your manuscripts at

http://www.hindawi.com
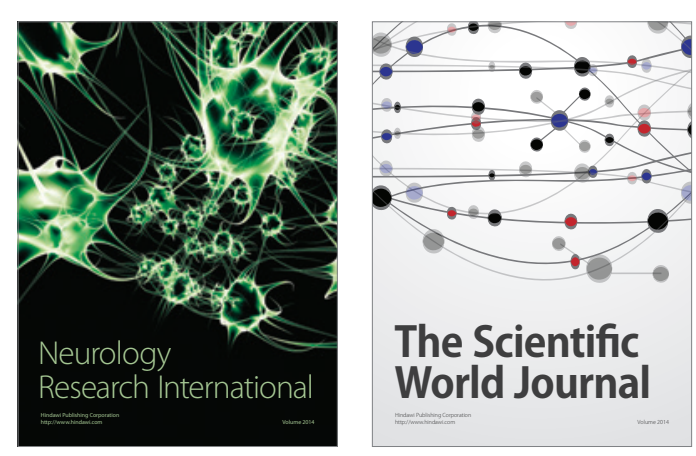

The Scientific World Journal

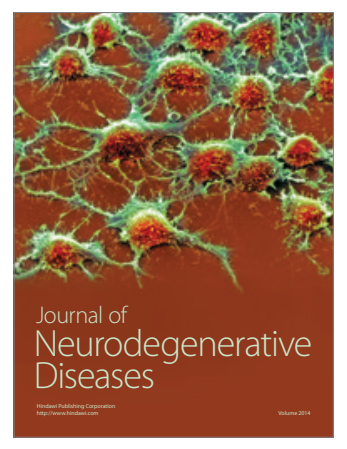

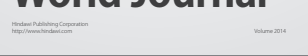

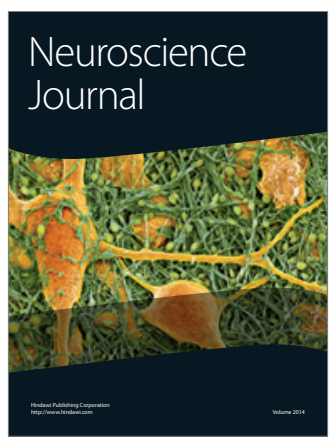

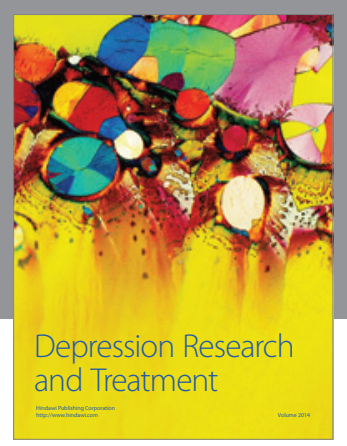
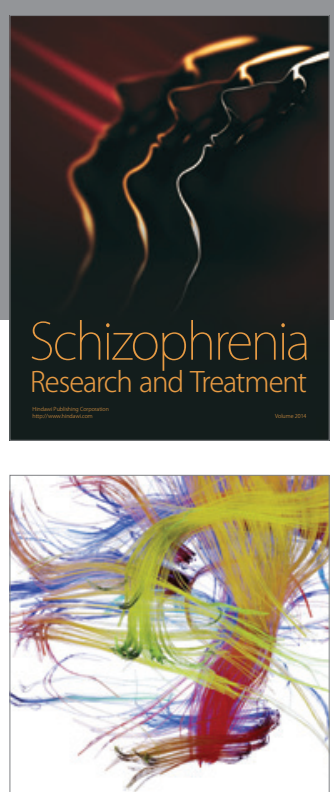

Brain Science

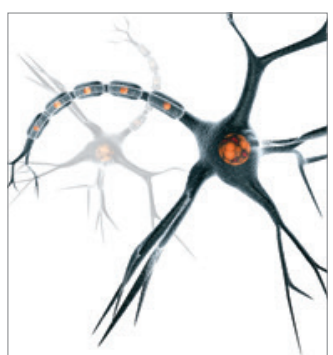

Neural Plasticity
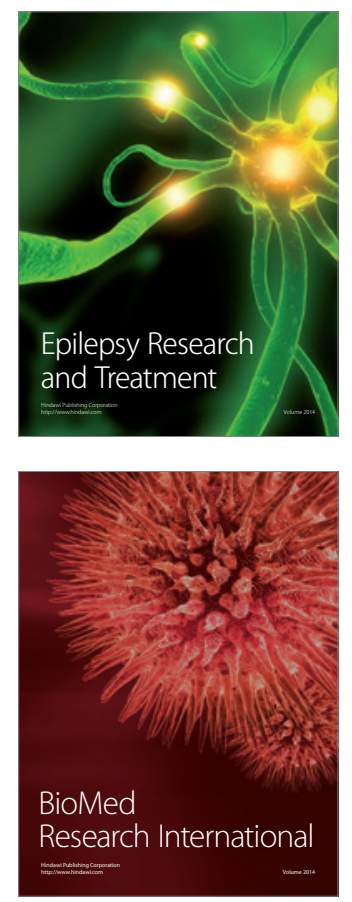

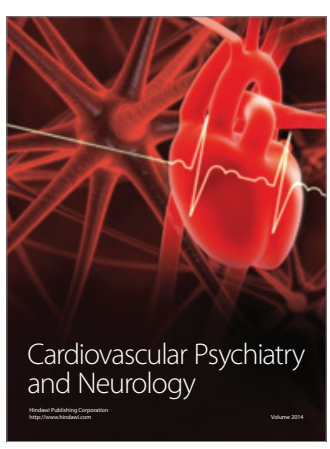

Parkinson's

Disease
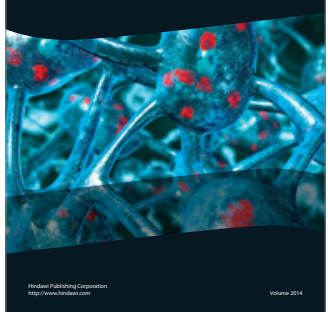